\title{
DE INVLOED VAN WERKTIJD, LOON EN RENTESTAND OP DE ARBEIDSPRODUCTIVITEIT.
}

\author{
Door Prof. Dr. J. Tinbergen.
}

In een artikel ,Methodologische vragen", verschenen in De Economist van Maart van dit jaar (blz. 175 e.v.) oefent Dr. Van Genechten kritiek uit op het „Onclerzoek omtrent de blijvende werkloosheid en haar bestrijding", verricht door de Commissie-Van der Waerden uit de Hoge Raad van Arbeid en door deze Raad gepubliceerd, en in het bijzonder op een door mij verzorgde bijlage welke aan dat Rapport is toegevoegd. Hij verdeelt zijn opinerkingen over drie onderwerpen, die ik bij deze beantwoording eveneens wil onderscheiden.

Onder het hoofd ,economische wetenschap en economische politiek" verwijt Dr. Van Genechten de leden der commissie dat zij (evenals de klassieke economen), het schena, waarvan zij bij hun wetenschappelijke beschouwingen uitgingen zonder meer op de problemen van practische politiek toepasten, zonder zich voldoencle af te vragen of in de werkelijke maatschappij ... de voorwaarden waren vervuld die zij bij hun wetenschappelijke beschouwingen bewust of onbewust hadden verondersteld." Hij adstrueert deze uitspraak aan de aanbeveling die de commissie geeft voor spreiding van het werk, zodat gemiddeld in plaats van 48 uur per week 40 uur wordt gewerkt. Bij deze aanbeveling noent de commissie $\mathrm{nl}$. het percentage waarmee, volgens mijn berekeningen, de werkgelegenheid zou toenemen ${ }^{1}$ ). De heer Van Genechten is van oordeel dat hier te grote stelligheid wordt gesuggereerd. Hij had blijkbaar meer reserves willen zien geformuleerd. Hij spreekt deswege van "Spielerei” en van ,de meest wilde fantasie”; en wijst

1) Terecht wijst Dr. $v$. G. daarbij op een fout in tabel XV, waardoor de gevolgen van werktijdverkorting iets te ongunstig worden voorgesteld; het setal 16 moet zijn 23 . 
er op dat deze cijfers alleen gebaseerd zijn op een ,hypothetische maatschappij waarvan (ik) een schema (heb) opgesteld".

Dit laatste zal op de lezer wellicht de indruk maken alsof door mij b.v. gewerkt was met de soort hypothetische maatschappijen, waarmee Von Böhm-Bawerk en vele andere bekende economen, bij wijze van voorbeeld, in hun leerboeken werken en met behulp waarvan Dr. van Genechten, b.v. in zijn Prae-advies van 1929 voor de Nationale Vereniging tegen de Werkloosheid het vraagstuk van de technologische werkloosheid heeft besproken. Tegen die indruk wil ik mij verweren, omdat het model dat ik heb gebezigd met een zoveel groter aantal trekken van de werkelijkheid rekening houdt dan in bedoelde oudere modellen is geschied, dat het daarmee naar billijkheid niet op een lijn kan worden gesteld. Minutieus statistisch werk is daartoe verricht; vergelijkingen met twee andere landen zijn doorgevoerd; terwijl, om met allerlei complicaties rekening te houden, tien alternatieve schema's zijn opgesteld. Indien het geen foto is van de werkelijkheid, dan toch een tele-foto, terwijl de modellen van Von Böhm daarnaast futuristische schilderstukken zijn!

Overigens wil ik er nog op wijzen dat ten aanzien van de belangrijkste concrete kritiek die Dr. v. G. op dit onderdeel verderop maakt prompt in de beschouwingen der Commissie de reserve wordt gemaakt die nodig is. Deze kritiek, waarop ik terugkom, betreft mijn veronderstelling dat de arbeidsproductiviteit van de werktijd niet afhangt. Deze beperkende veronderstelling is in dezelfcle alinea waarin de gewraakte ,te nauwkeurige" percentages worden genoend herhaald. Een tweede reserve, nl. t.a.v. onverwachte psychologische factoren, is daar eveneens vermeld.

Daar de mate waarin van de werkelijkheid geabstraheerd is echter slechts kan blijken uit de concrete bezwaren die mijn criticus naar voren brengt, is het wellicht het beste tot de behandeling daarvan aanstonds over te gaan, hetgeen ons tot het tweede onderwerp voert.

Dit tweede onderwerp is getiteld: ,de mathematische methode". Van deze methode, die Dr. v. G. voor enkele zeer algemene doeleinden nog wel accepteert, getuigt hij dat ze weinig vooruitgang heeft gebracht om tot nauwkeurige resultaten te komen, doch , ,meer en meer er op neerkomt eenvoudige dingen in gecompliceerde termen weer te geven. $\mathrm{Hij}$ adstrueert dit aan de resultaten 
van het eerste deel mijner Volkenbondsonderzoekingen, welke hij echter wel wat eigenaardig weergeeft, door alleen van het voornaamste positieve resultaat te spreken. In deze onderzoeking zijn $\mathrm{m}$. i. de negatieve resultaten minstens zo belangrijk, t.w. dat de loop van de investeringbedrijvigheid weinig beïnvloed wordt door de rentestand, door de prijzen van investeringsgoederen, door het echo-principe en door het ,acceleration principle”. Hoe evident Dr. van Genechten het moge vinden ,dat de mensen liever het vlees dan de botten hebben... dus wanneer de zaken goed gaan... geneigd zijn... nieuwe bedragen te investeren", dit neemt niet weg dat in vele en gerenommeerde artikelen en boeken²) over het conjunctuurvraagstuk veel meer aandacht wordt geschonken aan sommige der vier door mij vrij onbelangrijk gevonden factoren dan aan de winst, die de belangrijkste factor bleek. Het heeft $m i j$ in dit verband tot voldoening gestemd dat een aantal economen van de universiteit te Oxford ditzelfde onderwerp zo belangrijk achtten dat $z$ ij er een serie zorgvuldig voorbereide interviews van ondernemers aan wijdden, die eveneens tot het resultaat voerden dat de rentestand op de loop der investeringsactiviteit slechts ecn ondergeschikte invloed blijkt uit te oefenen.

Men versta mij goed: ik wil de betekenis van bedoeld Volkenbondsonderzoek niet overdrijven en zie er de tekortkomingen duidelijk van. In de wetenschap komen we nu eenmaal slechts door vallen en opstaan verder en in 't algemeen langzaam. Doch wanneer men schrijft over de betekenis van elk dier afzonderlijke stappen dient men evenmin naar de andere kant te overdrijven.

De heer Van Genechten ziet in dit werk en dat der hier aan de orcle zijnde nota een ,hang naar gecompliceerdheid". Ik kan hem verzekeren dat deze neiging mij evenzeer tegenstaat als hemzelf. Ik geloof echter dat de betrekkelijke gecompliceerdheid der gecritiseerde berekeningen geheel en al is toe te schrijven aan het onderwerp. De volkshuishouding is een gecompliceerd verschijnsel. Mijn eigen voorkeur is, als die van de meeste mede-onderzoekers, de zaken zo eenvoudig mogelijk voor te stellen. Wanneer ik daarbij

2) Ik noem van de recente literatuu bijv. Hayek, die aan de rentestand een belangrijke invloed toekent en Harrod, die aan het acceleration principle veel gewicht rerleent. Vaak wordt voorts de verwachting uitgesproken dat prijsverlaging van kapitaalgoederen belangrijk tot bestrijding van de depressie kan bijdragen. 
echter de werkeliikheid te veel geweld aandoe riskeer ik kritiek en ongeloof mijner collega's. Men zie slechts wat Dr. Van Genechten $m i j$ in het eerste gedeelte zijner beschouwingen verwijt: schematiseren. Ik bevind mij dus voor de moeilijkheid dat ik enerzijds van de (gecompliceerde) werkelijkheid niet te ver mag afwijken, want dan bega ik ,de meest wilde fantasie"; anderzijds mag ik niet gecompliceerd zijn.

Dr. Van Genechten geeft als voorbeeld de behandelingswijze van het vraagstuk: hoe werkt werktijdverkorting op de werkgelegenheid. De door mij vermelde uitkomst blijkt weinig af te wijken van een omgekeerde evenredigheid: verkorting van de werktijd in reden van 6 tot 5 geeft een verhoging van werkgelegenheid van 5 op 6 . Natuurlijk geldt het hier het geval dat het uurloon en niet het weekloon constant blijft. Men is geneigd om dan te zeggen: dat had ik zo wel kunnen zien en dat zegt de heer v. G. dan ook. Er zijn echter gezaghebbende critici die het anders inzien; die nl. uit de verhoogde druk der afschrijvingen die bij zulk een werkspreiding zou kunnen optreden slechte gevolgen vrezen voor ons concurrentievermogen in het buitenland. Mijn berekeningen geven aan de - gecompliceerde - reacties die claarbij in 't spel zijn ook aandacht. Deze reacties zijn o.m. dat een zekere prijsverhoging optreedt, claardoor verminderde afzet in het buitenland en vermeerderde invoer uit het buitenland; beïnvloeding van binnenlandse inkomens en prijzen. Uit mijn berekeningen blijkt dat de gezamenlijke invloed dezer repercussies gering is. Ik betwijfel of dat nu ook zo gemakkelijk, ,zó te zien zou zijn geweest".

Daarbij komt nog dat het rekenapparaat, daarbij gebruikt, zonder verdere moeite mogelijk maakt om het geval te berekenen waarbij de weeklonen en niet de uurlonen gelijk blijven. Daarbij doen zich de repercussies via de buitenlandse concurrentie in sterk vergrote mate gevoelen en die zou men m.i. dan toch zeker niet gemakkelijk van te voren of zonder behulp van berekeningen hebben kunnen bepalen.

Gelukkiger is de heer Van Genechten dan ook m.i. in het punt dat hij illustreert met Jan Gendarm. Hij betoogt hier dat verwaarloosd is de stijging van de arbeidsproductiviteit die optreedt wanneer de arbeidsduur per dag daalt. Ik heb daarop het volgende te antwoorden.

Het verschijnsel is inderdaad aanwezig, doch gebonden aan de 
vourwaarcle dat men verkorting van werktijd per dag bekijkt. Invoering van wandelweken of minder dagen per week, alsmede van vacanties van langere duur zullen die stijging van arbeidsproductiviteit vrijwel niet vertonen. Voor deze laatste drie vormen van arbeidsspreiding blijven onze berekeningen dus juist.

Wat de omvang van het verschijnsel betreft, moet men niet overdrijven. Bij de overgang van de 14-urige op de 12-urige, enz. en van de 10-urige op de 8-urige werkdag was het van groter betekenis dan bij overgang van 8 op 7 uren. Voorts is in gevallen waar de machine het tempo bepaalt de invloed ook zwak.

Niettemin is er alles voor te zeggen om schattingen over de invloed van deze verwaarloosde factor te maken. Dit nu - cn ik beschouw dit als cen belangrijk loordeel van de gevolgde werkwijze - is zonder veel mocite mogelijk met bchulp van de in het rapport gegeven formules ${ }^{3}$ ). Dit is een wijze van benutting der formules die mij steeds voor de geest gestaan heeft. Ze staan, om zo te zeggen, klaar voor ieder die er verdere ,proeven" mee wil doen. Dat deze, ,proef" nog niet gedaan was is toe te schrijven aan de omstandigheid dat geen der lezers van het concept - en dit waren er vrij veel - de belangrijkheid van deze factor zo hoog aansloeg als Dr. v. G. Wel verre van het gehele schema onhoudbaar te maken - zoals mijn criticus veronderstellenderwijs oppert - laat zich deze relatie er in opnemen zonder aantasting van de methode.

Wij komen thans aan punt 3 van de kritiek, aan het grootste bezwaar van den heer Van Genechten. Dit punt leidt hij in door (A) de theorie van Von Böhm-Bawerk en door hem daarin aangebrachte verbeteringen over de samenwerking der productiefactoren natuur, arbeid en kapitaal te resumeren en vervolgens te betogen dat (B) ik deze theorie aanvaard, (C) de consequenties

3) Nemen wij bijv aan dat bij verkorting van de werkweek van 48 uur tot 40 tur, de hoeveelheid product per arbeidsweek niet afneemt in de verhouding van 6 tot 5 , doch van 6 tot $5 \%$. Dan zal $\triangle g=\frac{1}{11} \times 0.24=$ 0.022 zijn en bij constant weekloon zal dan de werkgelegenheid toenemen met (volgens de formules in de eerste alinea van $\S 33$ gebruikt) $1.46 \times$ $0.022=3.2 \%($ geval XII) of $1.60 \times 0.022=3.5 \%$ (tabel XIV). Voor werktijdverkorting net constant uurloon worden de resultaten in de vier gevallen in tabel XV genoemd resp. 19, 20, 11 en $14 \%$. 
echter niet aanvaard, doch (D) dit feit verdoezel door op ondergeschikte punten de factoren in te schakelen die ik op het hoofdpunt verwaarloos. (Bovenstaande woordkeuze is niet precies die van $\mathrm{Dr}$. v. G.).

In antwoord hierop wil ik beginnen met op te merken dat ik de theorie van Von Böhm, al of niet geamendeerd door v. Genechten, slechts zeer ten dele aanvaard. De redenen daartoe liggen ten dele in de omstandigheid dat die theorie niet voldoende past op de problemen die mij bezighielden: $z \mathrm{ij}$ is statisch in de meest beperkte zin van het woord. Dat komt ten eerste reeds tot uitdrukking in het feit dat Böhm van een gegeven stand van de techniek uitgaat en wij ons in het bijzonder voor de gevolgen van de ontwikkeling der techniek interesseerden. Er is daardoor bij ons de vrijheid om zowel de productiviteit van de arbeid als de kapitaalintensiteit zich te laten veranderen, zonder dat deze aan elkaar gebonden zijn door "de curve der technische mogelijkheden".

Het statisch karakter der theorie blijkt ook uit het feit dat zij zich bezighoudt met een evenwichtstoestand die zich pas na zeer lange tijd zou verwezenlijken indien gedurende die lange tijd alle „data" (in het bijzonder de technische gegevens) constant zouden blijven. De lengte van deze tijd is gelijk aan de levensduur der betrokken kapitaalgoederen, van de orde van grootte dus van enige decennia. Ofschoon ik conjunctuurschommelingen uit mijn betoog elimineer, heb ik toch problemen beschouwd waarbij het om effecten van bepaalde maatregelen gaat op kortere termijn, b.v. na enkele jaren, hoogstens acht (één conjunctuurcyclus).

Indien men zich voor zulke effecten interesseert, kan men de theorie van Von Böhm alleen toepassen op nieuwe investeringen en vele der relaties die in Böhm's geval rigoureus zouden gelden, geiden dan niet meer. Bovendien komen m.i. dan andere aspecten meer op de voorgrond die in Böhm's theorie geheel verwaarloosd kunnen worden. Deze aspecten mag ik misschien samenvatten met het woord onderbezettingsvraagstukken.

Wij verkeren in een periode - althans vóór het uitbreken van de oorlog, toen het rapport werd geschreven - waarin zowel de arbeid als het kapitaal ten dele braak liggen. Voor een dergelijk verschijnsel is in Böhm's schema's geen plaats. Ten hoogste kan een der beide factoren ten dele braak liggen. Om deze zeer essentiële trek in het beeld op te nemen moest, meer dan dat in Böhm's schema geschiedt, met monetaire factoren worden gerekend, 
waarbij elementen van Keynes' leer konden worden benut. Wil men weten op welke plaats precies dit de redeneringen van Von Böhm en Van Genechten het meest wijzigt, dan zou ik zeggen: daar waar het gaat om de totale vraag naar goederen. Deze hangt bij de huidige organisatie der maatschappij sterk af van het inkomen doch is daaraan niet noodzakelijk gelijk - en van enkele elementen die men exogeen kan noemen; in het bijzonder de uitgavenpolitiek der overheid. In de door ons gebruikte schema's wordt dit element daarom zeer uitdrukkelijk ingevoerd. Ik kan het niet met Dr. van Genechten eens zijn als hij daarover zegt dat dat geschiedt , quasi-ongemerkt, onder een schijn van wetenschappelijke vaststelling".

Er zijn nog een paar verdere bezwaren tegen het stelsel van Von Böhm, doch deze zijn wel te verhelpen zonder ingrijpende wijzigingen, t.w. dat 10 . hij vrije concurrentie veronderstelt (zoals Van Genechten zelf ook releveert), in het bijzonder op de arbeidsmarkt, 2o. dat hij met het begrip „omweg” werkt, dat zo moeilijk in de realiteit te meten is (om die reden hebben wij aan het door ons gebruikte begrip van de kapitaalintensiteit de voorkeur gegeven) en 3o. dat hij het aanbod van kapitaal als volkomen onelastisch aanneemt. In een toestand van onderbezetting van de productiefactoren is deze veronderstelling wel bijzonder onrealistisch. Wij komen op de gevolgen daarvan terug.

Voorzover in ons werk de gedachtengang van Von Böhm gevolgd is, betreft dit de aanvaarding van de zienswijze dat de verhouding waarin in de productie de factoren arbeid en kapitaal gebruikt worden afhangt van de prijzen dezer factoren. Wij hebben claarbij niet aanstonds voor ,de prijs van kapitaal" gesubstitueerd "de rentestand"; in een toestand waarbij kapitaalgoederen braak liggen is het in de eerste plaats mogelijk on de kapitaalintensiteit der productie zonder kosten te verhogen. Voorzover kapitaalgoederen echter niet ,vrije goederen" zijn, is, in een geldhuishouding, de verkrijging niet slechts afhankelijk van de rentestand, maar ook van de kostprijs der kapitaalgoederen. Dit betekent echter in hoofdzaak een afhankelijkheid van het loon, waarover wij nog komen te spreken.

De aldus reeds gereduceerde invloed van de rentestand wordt nog minder, wanneer om redenen van monetaire techniek de rentestand zich bijna niet behoeft te wijzigen om een desgewenst veel groter aanbod van krediet mogelijk te maken. Dit verschijnsel van 
de grote aanbodelasticiteit van geldkapitaal is zelfs niet van vandaag of gisteren. Reeds vóór 1914 waren de veranderingen in de rentestand dic zich, valn jaar op jaar, in Engeland vertoonclen zeer gering. Men raadplege slechts de cijfers! De grootste wijziging in één depressieperiode was slechs enkele tiendedelen van een procent. Bij geringe veranderingen in de rentestand is de invloed van veranderingen in de rentestand op de omweg ook gering, zelfs indien de elasticiteit van de omweg t.o.v. de rentestand niet nul is. Daarbij komt dan nog de mogelijkheid dat zelfs deze elasticiteit - l.w.z. de procentueele verandering in omweg als gevolg van een verhoging met één honderdste van de rentestand - gering is. I $\mathrm{k}$ heb de indruk dat deze elasticiteit inderdaad niet groot is. Doch dat kan mis wezen. Het tegendeel is echter evenzeer moeilijk aan te tonen.

Laten wij echter aannemen dat de invloed van de rentestand op de wijzigingen in de omweg wèl belangrijk is. Dan brengt de door ons gekozen werkwijze mede, zoals wij boven reeds zeiden bij de behandeling van het werktijdvraagstuk, dat daarmede rekening kan worden gehouden zonder dat de door ons verrichte arbeid vruchteloos is geweest. Men moet dan de wijzigingen in de kapitaalintensiteit $(\triangle h)$ en de arbeidsproductiviteit $\left(\triangle g^{-1}\right)$ niet als onafhankelijk aannemen, maar als, althans ten dele, afhankelijk van de rentestand. Deze laatste moet dan, omdat hij in ons stelsel als veranderlijke niet voorkomt, door een afzonderlijke vergelijking worden verklaard. Bouwstenen voor een dergelijke vergelijking zijn te halen uit het onderzoek van de monetaire sfeer in Vol. II van ons Volkenbondsonderzoek.

Om geheel duidelijk te zijn, wil ik dus toegeven dat de invloed van de rentestand op de kapitaalintensiteit en de productiviteit der productie inderdaad zijn verwaarloosd, doch dat in het bovenstaande daarvoor m.i. enige goede redenen zijn aangegeven. Toegegeven zij eveneens dat de door Dr. v. G. op blz. 195 gewraakte zinsnede in dit verband misverstand kan wekken.

Anders staat het echter met de door Dr. Van Genechten vermeende verwaarlozing van de looninvloed op de rationalisatie. Hier moet ik een misverstand bij mijn criticus veronderstellen. De invloed van loonsverhogingen op de rationalisatie is niet alleen genoemd (waarbij dan, zoals Dr. v. G. terecht opmerkt, Åkerman's onderzoek wordt aangehaald), doch ook verwerkt in de berekeningen. Ten onrechte schrijft Dr. v. G. dan ook op blz. 193 dat 
deze „daarna bij de beschouwingen (wordt) geëlimineerd". Juist omdat die invloed blijkens Ảkerman's onderzoek wel belangrijk was - ofschoon slechts ruw te meten - zijn op blz. 227 van onze nota diens cijfers in de berekeningen opgenomen, met het resultaat dat de elasticiteit van de vraag naar arbeid 0.79 wordt in plaats van 0.16 (in geval $\mathrm{H}_{1}$ ) en 1.17 in plaats van 0.92 (geval $\mathrm{H}$ ).

Jan Gendarm en het komisch effect dat de heer Van Genechten in onze desbetreffende berekeningen ziet kunnen hier dus thuis blijven, evenals de paragraaf gewijd aan de door mij bewandelde zijpaden. Integendeel pretendeer ik een poging te hebben ondernomen tot het schatten van de elasticiteit van de vraag naar arbeid die redelijk volledig is en die de vergelijking van het tot nu toe op dit gebied gepresteerde kan doorstaan.

Deze verdediging van onze werkwijze zou ik willen laten volgen door de vraag aan den heer Van Genechten, welke der practische conclusies omtrent de bestrijding van de werkloosheid z.i. worden aangetast door de verwaarlozing van de invloed van de rentestand en welke conclusies hij daarvoor in de plaats zou willen stellen. Ik kan mij nl, moeilijk voorstellen dat, wat de economische (dus niet sociologische) conclusies betreft, zijn kritiek veel wijziging kan brengen.

Samenvattend ben ik in het bovenstaande dus tot de volgende stellingen geraakt:

1. Het door ons gebruikte model is veel realistischer dan de in de literatuur gangbare, in 't bijzonder dat van Von Böhm en Van Genechten;

2. Niet de methode van onderzoek is gecompliceerd, doch het onderwerp;

3. Verhoging van productiviteit bij werktijdverkorting kan slechts belangrijke invloed bij één der vier aanbevolen vormen van arbeidsspreiding hebben;

4. Deze invloed kan met geringe moeite in rekening gebracht worden juist dank zij de gevolgde werkwijze;

5. De theorie van Von Böhm helpt ons niet in een toestand van chronische onderbezetting van de beide productiefactoren arbeid en kapitaal;

6. De invloed van veranderingen in de rentestand op de produc- 
tieomweg is gering wanneer de rentestand weinig verandert, hetgeen in een toestand van chronische onderbezetting en van elastisch kredietaanbod aannemelijk is; deze invloed is door ons inderdaad verwaarloosd;

7. De invloed van het loon op de anbeidsproductiviteit is niet verwaarloosd. 